\title{
A AGRICULTURA FAMILIAR RUMO À PRODUÇÃO ORGÂNICA
}

\author{
Wagner Kazuyoshi Shimada* \\ João Gilberto Mendes dos Reis** \\ Antonio Carlos Vaz Lopes*** \\ Oduvaldo Vendrametto**** \\ Euclides Reuter de Oliveira ${ }^{* * * * *}$
}

RESUMO: A representatividade econômica, social e ambiental da agricultura familiar é cada vez mais reconhecida pelos governos e pela sociedade. Os movimentos sociais a favor do meio ambiente recaem sobre a atividade agrícola, exigindo metodologias alternativas de produção sustentável. Apesar do cenário favorável à produção orgânica aos empreendimentos de agricultura familiar, vários problemas recaem sobre essa atividade. Neste contexto, o objetivo desta pesquisa é apresentar a situação e características do setor na cidade de Dourados (MS), e identificar o método de produção mais viável aos pequenos produtores, utilizando de um modelo de decisão multicritério, baseado em um estudo de caso junto a um grupo de produtores orgânicos da região. Os resultados indicam o método de produção orgânico como o mais adequado aos empreendimentos familiares, considerando os critérios "produção", "mercado" e "logística".

PALAVRAS-CHAVE: Comportamento do Consumidor; Dourados (MS); Método de Decisão Multicritério; Orgânico.

\section{FAMILY AGRICULTURE TOWARDS ORGANIC PRODUCTION}

ABSTRACT: Economic, social and environmental representativeness of family agriculture is increasing being acknowledged by governments and society. Pro-environment social movements focus on agricultural activities and require alternative methodologies for sustainable production. In spite of a favorable scenario for organic

\footnotetext{
Mestre. Coordenador Administrativo da Faculdade de Engenharia da Universidade Federal da Grande Dourados (FAEN/UFGD), Brasil. E-mail: wagnershimada@gmail.com.

** Doutor em em Engenharia de Produção. Docente Titular da Universidade Paulista (UNIP) no Programa de Pós-Graduação em Engenharia de Produção e Pós-Graduação em Administração. Docente da Pós Graduação em Agronegócios da Universidade Federal da Grande Dourados (UFGD), Brasil.

*** Doutor em Administração. Docente na Faculdade de Administração, Ciências Contábeis e Economia da Universidade Federal da Grande Dourados (UFGD), Brasil.

**** Doutor em Engenharia de Produção. Docente Titular da Universidade Paulista (UNIP) no Programa de Pós-Graduação em Engenharia de Produção, Brasil.

***** Doutor em Zootecnia. Docente na Universidade Federal da Grande Dourados(UFGD), Brasil.
} 
production compounding family agriculture, several issues are proper to the activity. Current research provides the situation and characteristics of family agriculture in Dourados MS Brazil, and identifies the most viable production method of small producers through a multi-criteria decision method based on a case study with a group of organic producers of the region. Results reveal that the method of organic production is the most adequate for family entrepreneurs according to production, market and logistic criteria.

KEY WORDS: Consumer behavior; Dourados, Brazil; Multi-criteria Decision Method.

\section{INTRODUÇÃO}

A relevância da agricultura familiar no âmbito econômico e social já é amplamente reconhecida pelos governos e pela sociedade. No cenário mundial, segundo a FAO (2014a), nove em cada dez das 570 milhões de propriedades agrícolas são geridas por famílias, sendo a agricultura familiar a forma predominante de agricultura, responsável por cerca de $80 \%$ dos alimentos do mundo.

No Brasil, as agroindústrias e as grandes propriedades rurais dominam a produção agrícola voltada para a exportação, enquanto a agricultura familiar é a responsável por 70\% dos alimentos consumidos internamente no país (FAO, 2014a; MDA, 2015).

Os agentes econômicos da agricultura familiar ou pequena agricultura, como já foi chamada, diferem do grande empresário rural, não pelo tamanho, mas pelos valores sociais ou, diga-se, valores emocionais que os norteiam. Eles valorizaram a terra pelo seu contato diário, diversamente do grande empresário que se relaciona com a terra pela renda fundiária, ou seja, apenas pela relação racional de interesse e puramente instrumental (BUAINAIN et al., 2014).

A agricultura familiar também se destaca na questão ambiental. A atividade agrícola familiar destaca-se pela preocupação com o meio ambiente e utilização de metodologias alternativas de produção que minimizam os danos à terra, à água e ao ar, como é, por exemplo, o sistema orgânico de produção (KOHLRAUSCH et al., 2009). 
Segundo Azevedo (2006), o método orgânico de produção utiliza técnicas que visam o respeito ao meio ambiente e a qualidade do alimento através da não utilização total, ou mínima possível, de agrotóxicos ou qualquer outro tipo de produto que possa causar dano ao meio ambiente ou à saúde dos consumidores.

Conforme a Lei 10.831/03, a finalidade de um sistema de produção orgânico é, dentre outras, a oferta de produtos saudáveis e isentos de contaminantes, o uso saudável do solo, da água e do ar, reduzindo as formas de contaminação desses elementos pelas práticas agrícolas, o incentivo à integração entre segmentos da cadeia produtiva e de consumo de produtos orgânicos, e o uso de métodos cuidadosos, com o propósito de manter a integridade orgânica e as qualidades vitais do produto em todas as etapas (BRASIL, 2015).

Contudo, como qualquer outra atividade, a produção orgânica também possui gargalos. Alguns deles, abordados por Moretti (2014), Padua (2014) e Lijerón (2006), são: problemas na logística e na comercialização dos produtos, falta de crédito específico para a agricultura orgânica, pouca experiência e informação técnica, dificuldade no controle de pragas e doenças, e carência de assistência técnica.

Diante disso, a pergunta que surge é: com todos esses entraves e demais peculiaridades da atividade, qual é o método de produção mais viável para os pequenos empreendimentos familiares: a produção orgânica ou a produção convencional?

A fim de responder a citada questão, o objetivo deste trabalho é apresentar aspectos da produção orgânica brasileira, com ênfase na região de Dourados, Mato Grosso do Sul, e verificar a metodologia de produção mais adequada aos pequenos produtores, através de um estudo de caso junto à feira orgânica da comunidade quilombola Dezidério Felipe de Oliveira.

\section{REFERENCIAL TEÓRICO}

\subsection{OS CENÁRIOS DA PRODUÇÃO ORGÂNICA}

O Instituto de Pesquisa de Agricultura Orgânica - FiBL (sigla do alemão: Forschungs institut für biologischen Landbau) é um instituto de pesquisa indepen- 
dente, sem fins lucrativos, com o objetivo de desenvolver a ciência no campo da agricultura orgânica. Junto à International Federation of Organic Agriculture Movements - IFOAM disponibilizam dados estatísticos e indicadores atualizados, que servem como uma importante ferramenta para autoridades e gestores políticos, indústrias, pesquisadores e profissionais de extensão. Os dados apresentados pela FiBL e IFOAM tornaram-se os mais citados em artigos científicos, técnicos e descritivos e relatórios sobre agricultura orgânica (WILLER; LERNOUD, 2015).

No Quadro 1, observam-se alguns indicadores da agricultura orgânica mundial, considerando os 170 países com dados de certificação orgânica cadastrados no FiBL e no IFOAM até 2013. Os países com maior área orgânica cultivada são a Austrália (17,2 milhões de hectares), a Argentina (3,2 milhões) e os Estados Unidos (2,2 milhões). Dos 120 países cadastrados junto ao IFOAM, tem-se 815 propriedades orgânicas afiliadas até 2014.

Quadro 1. Indicadores da agricultura orgânica e países líderes 2015

(Continua)

\begin{tabular}{|c|c|c|}
\hline Indicador & Mundo & Países Líderes \\
\hline $\begin{array}{l}\text { Países com dados da } \\
\text { agricultura orgânica } \\
\text { com certificação }\end{array}$ & 2013: 170 países & - \\
\hline $\begin{array}{l}\text { Área de agricultura } \\
\text { orgânica }\end{array}$ & $\begin{array}{l}\text { 2013: } 43.1 \text { milhões de } \\
\text { hectares } \\
\text { (1999: } 11 \text { milhões de } \\
\text { hectares) }\end{array}$ & $\begin{array}{l}\text { Austrália (17.2 milhões de hectares); } \\
\text { Argentina ( } 3.2 \text { milhões de hectares); } \\
\text { EUA (2.2 milhões de hectares, 2011). }\end{array}$ \\
\hline Produtores & $\begin{array}{l}\text { 2013: } 2 \text { milhões de pro- } \\
\text { dutores } \\
\text { (2012: } 1.9 \text { milhões de } \\
\text { produtores; 2011: } 1.8 \\
\text { milhões de produtores) }\end{array}$ & $\begin{array}{l}\text { Índia (650’000); } \\
\text { Uganda (189'610; 2012); } \\
\text { México (169'703). }\end{array}$ \\
\hline
\end{tabular}


(Conclusão)

\begin{tabular}{|c|c|c|}
\hline Indicador & Mundo & Países Líderes \\
\hline $\begin{array}{l}\text { Mercado de } \\
\text { produtos orgânicos }\end{array}$ & $\begin{array}{l}\text { 2013: } 72 \\
\text { bilhões de dólares } \\
\text { (1999: } 15.2 \\
\text { bilhões de dólares) }\end{array}$ & $\begin{array}{l}\text { EUA ( } 24.3 \text { bilhões de dólares); } \\
\text { Alemanha ( } 7.6 \text { bilhões de euros); } \\
\text { França ( } 4.4 \text { bilhões de euros). }\end{array}$ \\
\hline Consumo per capita & 2013: 10,05 dólares & $\begin{array}{l}\text { Suíça ( } 210 \text { euros); } \\
\text { Dinamarca (163 euros); } \\
\text { Luxemburgo (157 euros). }\end{array}$ \\
\hline $\begin{array}{l}\text { Número de países com } \\
\text { regulamentação de } \\
\text { produção orgânica }\end{array}$ & 2013: 82 países & - \\
\hline $\begin{array}{c}\text { Número de afiliados à } \\
\text { IFOAM }\end{array}$ & $\begin{array}{l}\text { 2014: } 815 \text { afiliados de } \\
120 \text { países }\end{array}$ & $\begin{array}{l}\text { Alemanha: } 89 \text { afiliados; } \\
\text { China: } 55 \text { afiliados; } \\
\text { EUA: } 51 \text { afiliados; } \\
\text { Índia: } 47 \text { afiliados. }\end{array}$ \\
\hline
\end{tabular}

Fonte: Adaptado de FiBL e IFOAM (2015).

Segundo informações da FiBL e IFOAM (2015), mundialmente, o Brasil ocupa a $11^{a}$ posição na questão de maior área destinada à produção orgânica. Com 0,7 milhões de hectares, é a terceira maior área orgânica cultivada na América Latina. Tem-se a Argentina com 3,2 milhões de hectares e o Uruguai, com 0,9 milhões de hectares.

Outro importante indicador é o tamanho do mercado consumidor de produtos orgânicos, estipulado em 72 bilhões de dólares, tendo como principais países consumidores: os Estados Unidos (24,3 bilhões de dólares), a Alemanha (7,6 bilhões de euros) e a França ( 4,4 bilhões de euros). O desenvolvimento do mercado mundial cresceu quase cinco vezes de 1999 a 2013. Na América Latina, o Brasil é o maior mercado consumidor (SAHOTA, 2015).

O último censo agropecuário, realizado em 2006 pelo IBGE, identificou 
90.497 estabelecimentos com produção orgânica, divididos em grupos de atividades. Segundo a pesquisa, a porcentagem da produção exportada vai de encontro à conjuntura favorável do mercado externo por produtos orgânicos, sendo que 60\% da produção total do país é enviada principalmente para o Japão, Estados Unidos e União Europeia (IBGE, 2009). Das 90.497 propriedades, apenas 5.106 possuíam algum tipo de certificação. A baixa adoção de certificação por parte dos produtores orgânicos é reflexo das deficiências do setor, como: o baixo nível de escolaridade, o acesso limitado à assistência técnica e a reduzida participação em organizações sociais (IBGE, 2009).

Dados do Ministério da Agricultura, Pecuária e Abastecimento - MAPA apontam que, entre janeiro de 2014 e janeiro de 2015, o número de agricultores que optaram pela produção orgânica com certificação passou de 6.719 para 10.194, um aumento de cerca de 51,7\%. O Nordeste é a região com maior número de produtores orgânicos, com pouco mais de 4.000, seguido do Sul (2.865) e Sudeste (2.333) (MAPA, 2015).

A adesão de mais produtores brasileiros ao mercado de orgânicos disponibiliza alimentos mais saudáveis à população, e promove a conservação e a recomposição dos ecossistemas. O Sudeste é a região com maior área produtiva, com 333 mil hectares. Em seguida, estão as regiões Norte (158 mil hectares), Nordeste (118,4 mil hectares), Centro-Oeste (101,8 mil hectares) e Sul (37,6 mil hectares) (MAPA, 2015).

\subsection{A PRODUÇÃO ORGÂNICA EM DOURADOS - MATO GROSSO DO SUL}

Estudos de Padua (2014) verificaram ampla diversidade na produção orgânica familiar no Estado, sendo que nos estabelecimentos pesquisados constataram-se as produções de: hortaliças (63\%), frutas em geral (47\%), milho (35\%), mandioca (27\%), maracujá (17\%), galinha caipira (16\%), abóbora (15\%), feijão (13\%), limão (13\%), cana (12\%), mel (11\%) e café ( $8 \%)$.

No que se refere ao método de produção orgânico, os pequenos produtores são considerados os precursores da atividade no Estado de Mato Grosso do Sul, e fundadores, em 09 de setembro de 2000, da Associação dos Produtores de Orgânicos do Mato Grosso do Sul - APOMS, com sede no município de Glória de Dourados 
(MS) (LIJERÓN, 2006; MORETTI, 2014).

$\mathrm{Na}$ análise histórica da região da Grande Dourados, três momentos marcantes na produção da identidade dominante do local estão diretamente ligados à exploração da terra: o extrativismo (meados do século XIX, início do século XX), a Colônia Agrícola Nacional de Dourados - CAND (iniciativa do Governo Federal para a colonização da fronteira, a partir dos anos de 1940 e 1950), e o processo de modernização do campo (a partir da década de 1970) (MORETTI, 2014).

Pode-se identificar, na região em análise, três grupos de produtores orgânicos: "os independentes", que são aqueles com fortes laços com a terra e que se preocupam com o consumo de produtos saudáveis, não tendo a questão financeira (lucro) como motivação; "os fragilizados", que são aqueles dependentes de ajuda técnica e operacional do Estado, sem infraestrutura de produção e sem capacidade de atuarem de modo independente; e "os produtores organizados em associação", organizados e articulados com o poder público, elaboram projetos e dialogam com o Estado (MORETTI, 2014).

As dificuldades da atividade na cidade de Dourados, identificadas nos estudos de Moretti (2014) e Padua (2014), são semelhantes às identificadas por Lijerón (2006) em outras regiões e países, como: falta de organização produtiva, escassez de recursos financeiros, falta de experiência e assistência técnica, escoamento da produção inadequado, dificuldade no controle de pragas e doenças, e outras.

\section{METODOLOGIA}

Trata-se de uma pesquisa exploratória e descritiva, considerando que o seu objetivo é proporcionar uma visão geral e descrição de características acerca de um determinado fenômeno, através de levantamento bibliográfico e documental, e estudo de caso (GIL, 2010). As etapas se deram conforme descrição abaixo:

a) Realizou-se um estudo a partir de artigos científicos e instituições envolvidas com a agricultura familiar e a produção orgânica, com o objetivo de identificar e fundamentar a situação e características do setor, além de 
assuntos relacionados ao trabalho, como a questão da sustentabilidade ambiental e a segurança alimentar.

b) Para confrontação dos dados obtidos à realidade local, optou-se pela realização de um estudo de caso junto à Comunidade Quilombola Dezidério Felipe de Oliveira, localizada no Distrito da Picadinha, na cidade de Dourados, Mato Grosso do Sul, a $18 \mathrm{~km}$ do perímetro urbano. Tal escolha foi em razão do relacionamento já existente com os produtores da comunidade, pelas atividades de assistência técnica e extensão rural - ATER exercidas constantemente pela Universidade Federal da Grande Dourados.

c) A coleta de dados foi realizada através de entrevista com questionário semiestruturado em dois períodos diferentes. A primeira foi entre julho e agosto de 2014, junto aos produtores quilombolas envolvidos na "feira orgânica", sendo 6 famílias no total. Nesta fase, obtiveram-se informações sobre a comunidade, a produção, os entraves e perspectivas da comunidade. Os questionários respondidos permanecerão em poder dos pesquisadores e a identidade dos envolvidos foi preservada utilizando-se siglas aleatórias neste trabalho. As falas foram transcritas literalmente, sem correções gramaticais e/ou ortográficas. A segunda coleta foi em agosto de 2015, com o mesmo grupo, para atendimento ao item seguinte.

d) $\mathrm{O}$ contexto dos fatores que impactam na decisão de se produzir itens orgânicos ou convencionais foi avaliado através da metodologia de análise hierárquica, tratada neste trabalho pela sigla AHP, do inglês Analytic Hierarchy Process. Os dados foram analisados utilizando o software Expert Choice ${ }^{\circledR}$ v. 11. E os resultados obtidos contribuíram na inferência das conclusões.

\subsection{A METODOLOGIA AHP}

O método Analytic Hierarchy Process - AHP é um instrumento de apoio para situações decisórias complexas, considerando critérios e subcritérios de hierarquia e avaliações paritárias. Foi criado na década de 70 pelo matemático Thomas Lorie Saaty, sendo então utilizado em diversas áreas, tanto para realizar escolhas em 
um processo decisório, quanto para justificá-las. O método é baseado em conceitos de álgebra linear, pesquisa operacional e psicologia (SAATY, 1991).

$O$ processo se inicia com a construção da hierarquia de acordo com o problema proposto. $\mathrm{O}$ tomador de decisão deve estruturar o problema em níveis, construindo uma árvore invertida, que demonstra um objetivo/meta da decisão e, em seguida, seus critérios e alternativas que serão avaliados, em fase posterior.

Tais critérios e subcritérios foram definidos por sua relevância na literatura consultada pelo pesquisador, sendo elas: produção, logística e mercado consumidor (MORETTI, 2014; PADUA, 2014; LIJERÓN, 2006).

Definida a estrutura hierárquica do problema, inicia-se a segunda fase do processo: a avaliação dos critérios e/ou alternativas paritariamente, ou seja, par a par. Para isso, é utilizada uma escala de 1 a 9, sendo que 1 significa "importância igual" e 9 "extrema importância", o que possibilitará a determinação da importância de cada critério, também chamada de "peso".

Considerando que o processo de decisão neste estudo (optar pelo método convencional ou pelo método orgânico de produção) envolve mais de um ator (os produtores entrevistados), a coleta de dados se deu de forma individual e, posteriormente, calculou-se a média geométrica das respostas para cada critério. Essa metodologia é cabível e recomendada ao estudo por se tratar de um processo de tomada de decisão em grupo com divergências de opiniões (ISHIZAKA, 2011). A equação (1) representa o cálculo utilizado para obter a média geométrica:

$$
M G=\sqrt[n]{a_{1} a_{2} \ldots a_{n}}
$$

sendo que $\mathbf{a}_{1} \mathbf{a}_{2} \ldots \mathbf{a}_{\mathbf{n}}$ são números positivos.

Após a determinação dos pesos de cada critério, o método AHP calcula os dados em forma de matriz, elevando-a a potências arbitrariamente altas, portanto, são comumente utilizados softwares específicos para o método. Nesta pesquisa, optou-se pelo software Expert Choice ${ }^{\circledR}$ v. 11, pela disponibilidade e praticidade do programa.

Com a devida alimentação do software, a integridade do julgamento dos cri- 
térios é calculada pelo índice de inconsistência. Quando o índice é maior que 0,10, considera-se que o tomador de decisão deve rever o peso de algum critério para que a decisão se torne consistente. O que ocorre somente quando o índice é menor ou igual a 0,10 (SAATY, 1991).

Concluindo, o AHP é um método que necessita de elementos fundamentais para auxiliar o tomador de decisão. Estruturar a árvore de dependência com um conjunto de critérios e subcritérios adequados, e a sua devida ponderação durante o processo de alimentação do software, garantem que o julgamento decisório seja conciso e robusto.

\subsection{A COMUNIDADE QUILOMBOLA, A UFGD E A FEIRA ORGÂNICA}

Localizada no Distrito da Picadinha, na cidade de Dourados, Estado de Mato Grosso do Sul, a $18 \mathrm{~km}$ do perímetro urbano, a Comunidade Quilombola Dezidério Felipe de Oliveira é uma comunidade reconhecida e devidamente registrada pela Fundação Cultural Palmares (FCP), desde abril de 2005.

Consideram-se quilombolas os descendentes de africanos escravizados que mantêm tradições culturais, de subsistência e religiosas ao longo dos séculos. Além de formalizar a existência destas comunidades, também são atribuições da FCP assessorar juridicamente e desenvolver projetos, programas e políticas públicas de acesso à cidadania. No território nacional estimam-se várias outras comunidades, além das 1.500 certificadas pela Palmares (FCP, 2014).

A Universidade Federal da Grande Dourados (UFGD), criada em 2006, possui duas unidades, a Unidade 1 - localizada na região central de Dourados (Rua João Rosa Góes, 1761 - Vila Progresso) e a Unidade 2 - localizada na rodovia Dourados-Itahum, Km 12, a 6 km da Comunidade Quilombola. Também administra o Hospital Universitário (HU), junto à Empresa Brasileira de Serviços Hospitalares - EBSERH, próximo ao início da rodovia a caminho da Unidade 2 (Rua Ivo Alves da Rocha, 558 - Altos do Indaiá).

Através do projeto intitulado "Transferência de Tecnologias Agronômicas Zootécnicas e Ambientais à Agricultura Familiar no Sudoeste de Mato Grosso do Sul”, de 2006, a comunidade recebeu assistência técnica visada apenas à produção 
de subsistência.

No decorrer dos anos, se tornou objeto de estudo para vários outros projetos, financiados pelo Conselho Nacional de Desenvolvimento Científico e Tecnológico (CNPq), Ministério da Educação (MEC), Coordenação de Aperfeiçoamento de Pessoal de Nível Superior (CAPES) e a UFGD, todos apoiados pela Pró-reitoria de Extensão e Cultura (PROEX/UFGD).

Somente a partir de 2014, o volume de produção da comunidade aumentou e gerou excedente agrícola. Diante disto, surgiu a possibilidade de comercialização desses produtos na Unidade 2 da UFGD, às terças e sextas-feiras pela manhã, ficando conhecida como "feira orgânica". Os principais consumidores são professores, servidores técnico-administrativos e alunos (MORETTI, 2014).

Com as vendas em alta, surgiu uma nova proposta de um espaço para vendas na Unidade I, às quintas-feiras. Iniciada em 21 de agosto de 2014, a repercussão positiva deste novo ponto resultou na indicação de outro possível local para vendas no HU, e na feira livre do bairro Parque Alvorada, em Dourados (MS). A comercialização nesses pontos ainda encontra-se em análise pelos idealizadores e produtores, pois eles não conseguem produzir a demanda estimada para todos os locais.

\section{RESULTADOS E DISCUSSÃO}

Através das entrevistas realizadas pode-se verificar que a área total da comunidade é de 41 hectares, dividida em 129 famílias. Porém, a maioria migrou para áreas urbanas e apenas 16 delas têm residência fixa no local. Das seis famílias que atuam na feira orgânica, tem-se uma média de três pessoas por família - pai, mãe e filho (a) - com renda mensal de um a três salários mínimos, sendo a feira orgânica a principal fonte de renda, e que as outras 10 famílias que residem na comunidade exercem empregos informais na UFGD ou no distrito de Picadinha. Elas não participam da feira orgânica por falta de interesse, mas cultivam alimentos para o consumo próprio.

Apurou-se também que as 113 famílias que migraram para áreas urbanas residem, parte no distrito de Picadinha, e parte em Dourados. Pela proximidade de 
aproximadamente seis quilômetros da UFGD ao distrito, muitos exercem empregos informais nas cantinas e restaurantes do campus universitário, o que inclui a Universidade Estadual de Mato Grosso do Sul (UEMS). Essas famílias utilizam as terras na comunidade com plantações para consumo próprio ou as arrendam.

Em relação à produção dos envolvidos na feira orgânica, observa-se que os produtores não mantêm nenhum tipo de controle referente a custos e volume de produção. O que fica enfatizado nas palavras de um dos produtores é: "o que for dando, a gente vai vendendo".

Este fato demonstra um caráter empírico nos processos de produção e corrobora as afirmações de Moretti (2014), quando ela retrata essa falta de organização produtiva e de comercialização como uma das principais dificuldades desses grupos de agricultores.

Apesar disso, a produção da comunidade é diversificada e apresenta boa aparência. Para demonstrá-las, registrou-se a imagem da Figura 1, em visita à feira orgânica, em 22 de agosto de 2014.

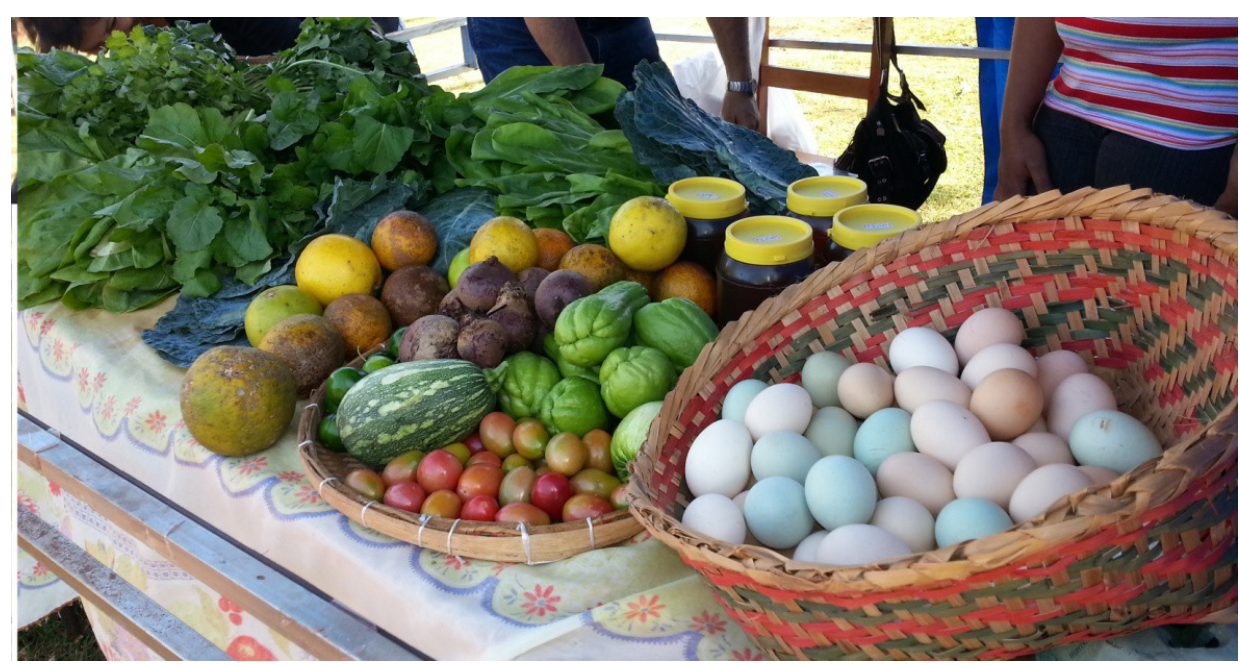

Figura 1. Feira Orgânica, Unidade II - UFGD.

Fonte: Acervo do autor.

A análise do critério "produção" através da metodologia AHP apresenta índice de inconsistência igual a 0,07 , o que torna a construção do processo consistente. 
A Figura 2, elaborada pelo autor com os dados levantados na pesquisa, expõe a ordem de relevância dos subcritérios de produção, julgados mais importantes pelos produtores, e o peso atribuído a cada um, considerando a priorização do método de produção convencional ou orgânico.

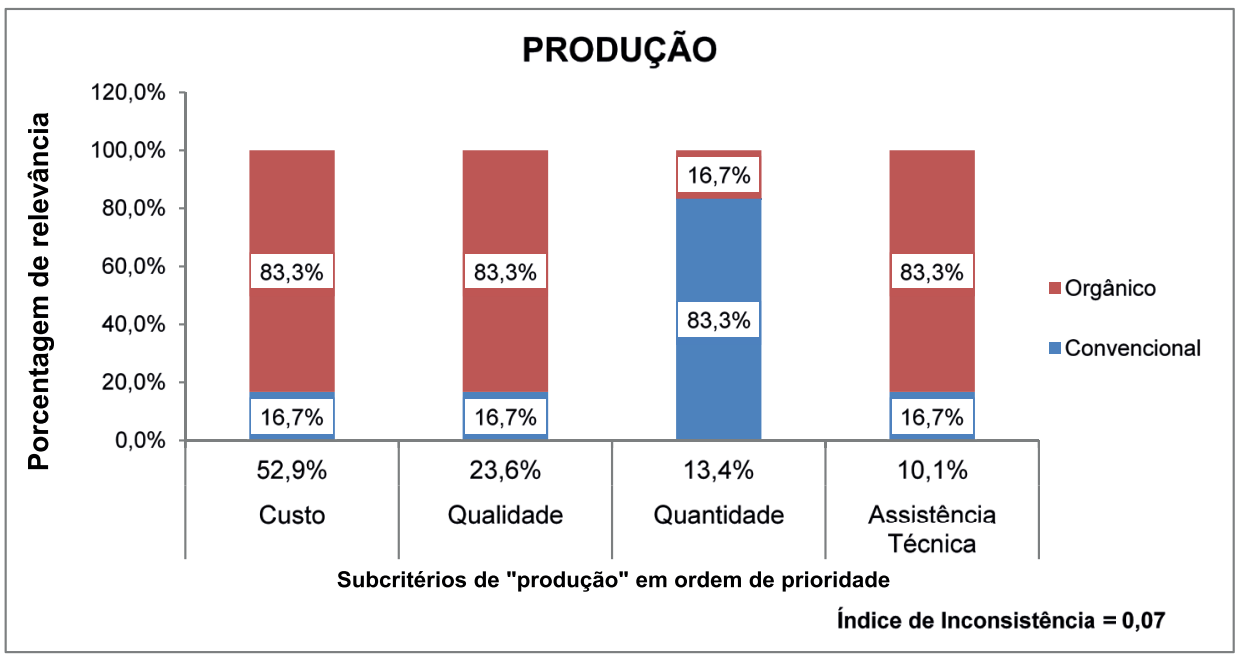

Figura 2. Priorização dos métodos de produção para os subcritérios de produção.

Acredita-se que o subcritério "custo" tenha maior relevância sobre os demais por incidir diretamente no preço final da mercadoria. Segundo Andrade e Bertoldi (2012), o preço é uma das principais limitações para os consumidores deste tipo de produto. Para os produtores, o método orgânico é mais vantajoso em relação ao convencional pela não necessidade de aquisição de insumos químicos, o que também justifica a priorização do método orgânico no subcritério "qualidade" e a priorização do método convencional no subcritério "quantidade".

Padua (2014) identificou uma maioria expressiva de agricultores que considera o custo de produção do sistema orgânico inferior ao sistema convencional, o que justifica a priorização do método em $83,3 \%$.

Sobre a priorização do método orgânico para o subcritério "Assistência Técnica", considera-se que a comunidade quilombola esteja inserida no grupo dos "fragilizados", classificação proposta por Moretti (2014), ou seja, aqueles que carecem e dependem de auxílio do Estado para o desenvolvimento da atividade.

Dos problemas relatados pelos entrevistados, destaca-se o baixo valor de 
crédito rural disponibilizado pelo Programa Nacional de Fortalecimento da Agricultura Familiar (PRONAF), em torno de dois mil e quinhentos reais, insuficientes segundo eles, para investimentos significativos na atividade.

Outro entrave identificado é a falta de veículos apropriados para o transporte das mercadorias do campo para os pontos de venda. O transporte é realizado apenas com um carro de passeio pequeno e uma moto, dos próprios produtores, o que limita a comercialização dos produtos. Confirma os relatos de Moretti (2014), e a própria análise do método AHP, que tem o subcritério "transporte" como o de maior prioridade $(49,3 \%)$ no critério "logística".

A Figura 3, construída pelo autor com as informações obtidas, demonstra a ordem de prioridade dos subcritérios do critério "logística" e seus respectivos pesos, atribuídos pelos produtores para a priorização do método orgânico ou convencional. O índice de inconsistência obtido é 0,05 , ou seja, uma avaliação consistente.

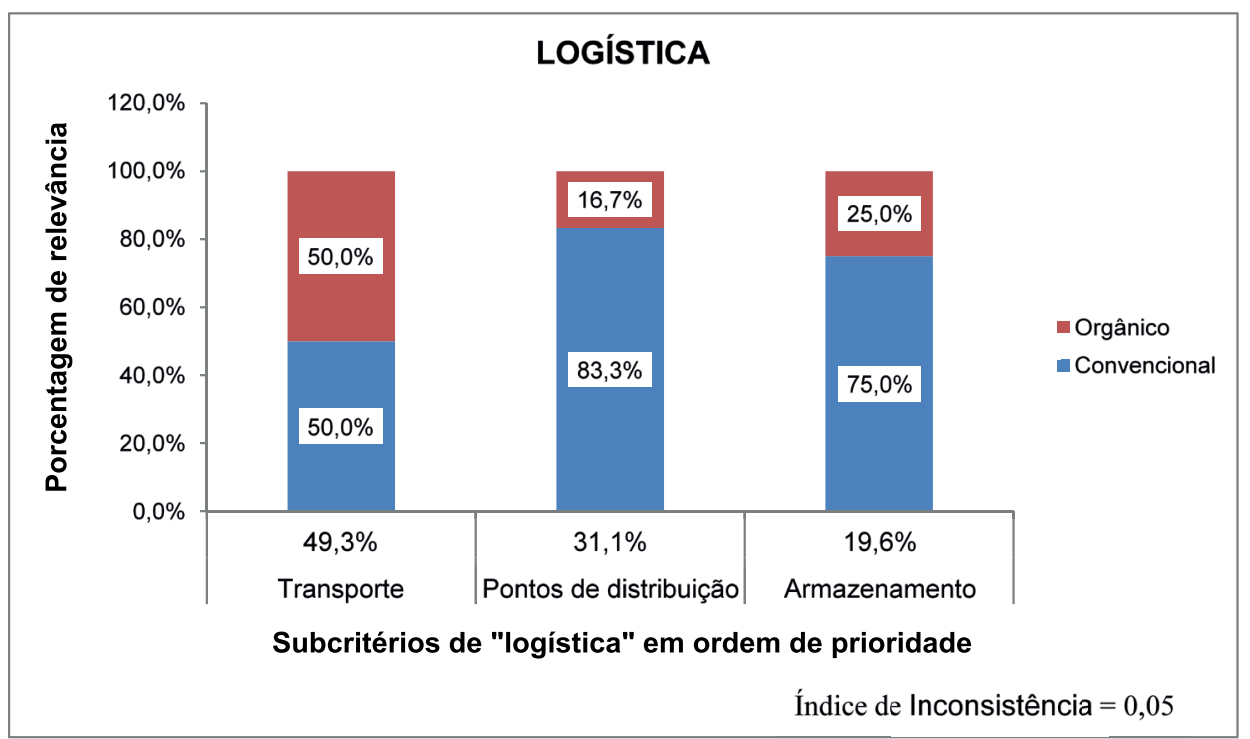

Figura 3. Priorização dos métodos de produção para os subcritérios de logística.

Em relação aos subcritérios "armazenamento" e "pontos de distribuição", os produtores não atribuíram importância ao método orgânico por não os aplicarem em sua realidade. Colhem apenas o que vão vender no dia, ou produzem pouco, 
nos casos de produtos orgânicos com beneficiamento (doces, compotas), não tendo problemas com estoque, armazenagem ou distribuição.

No critério "mercado", com os dados apresentados na Figura 4, o peso atribuído de 61,4\% para o subcritério "preço" é muito maior do que os demais. A priorização do método orgânico (83,3\%) é atribuída pelos produtores por acreditarem que a venda direta do produtor ao consumidor elimina atravessadores e influência nos preços, podendo ser até mais baixos do que em supermercados da região.

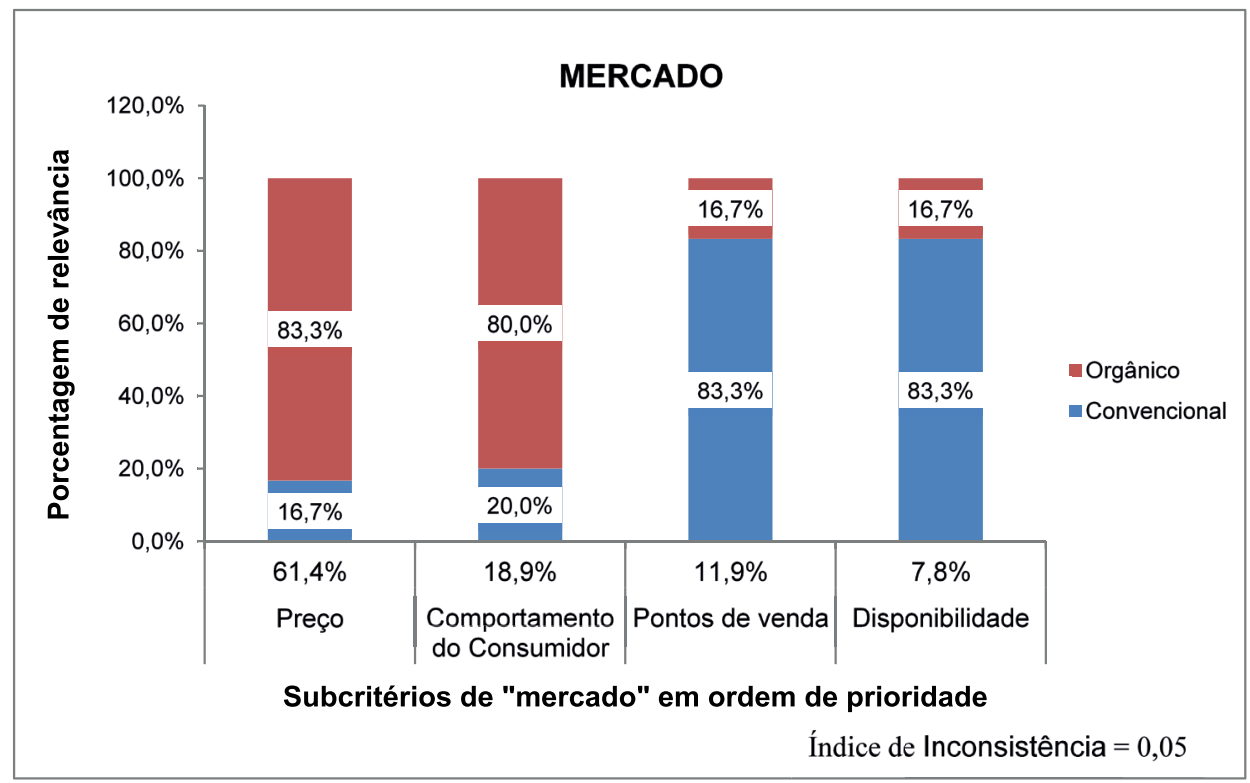

Figura 4. Priorização dos métodos de produção para os subcritérios de mercado.

Observa-se também que os produtores percebem o aumento da demanda por produtos orgânicos, constatado com o resultado de priorização do método orgânico em 80\% no subcritério "comportamento do consumidor". Conforme Andrade e Bertoldi (2012), o interesse pelo consumo de alimentos com maior valor nutritivo e a busca por hábitos de vida mais saudáveis contribuem para o aumento do consumo de alimentos orgânicos.

O método de produção convencional é priorizado nos subcritérios "pontos de venda" e "disponibilidade". Os pesos atribuídos para o critério "mercado" tornam 
o processo decisório consistente, pois o índice de inconsistência obtido é 0,05 .

Dado a análise dos subcritérios do modelo, tem-se a apresentação da priorização dos critérios estabelecidos para o processo de análise hierárquica, de acordo com as alternativas de método produção convencional ou orgânico, disposta na Figura 5 .

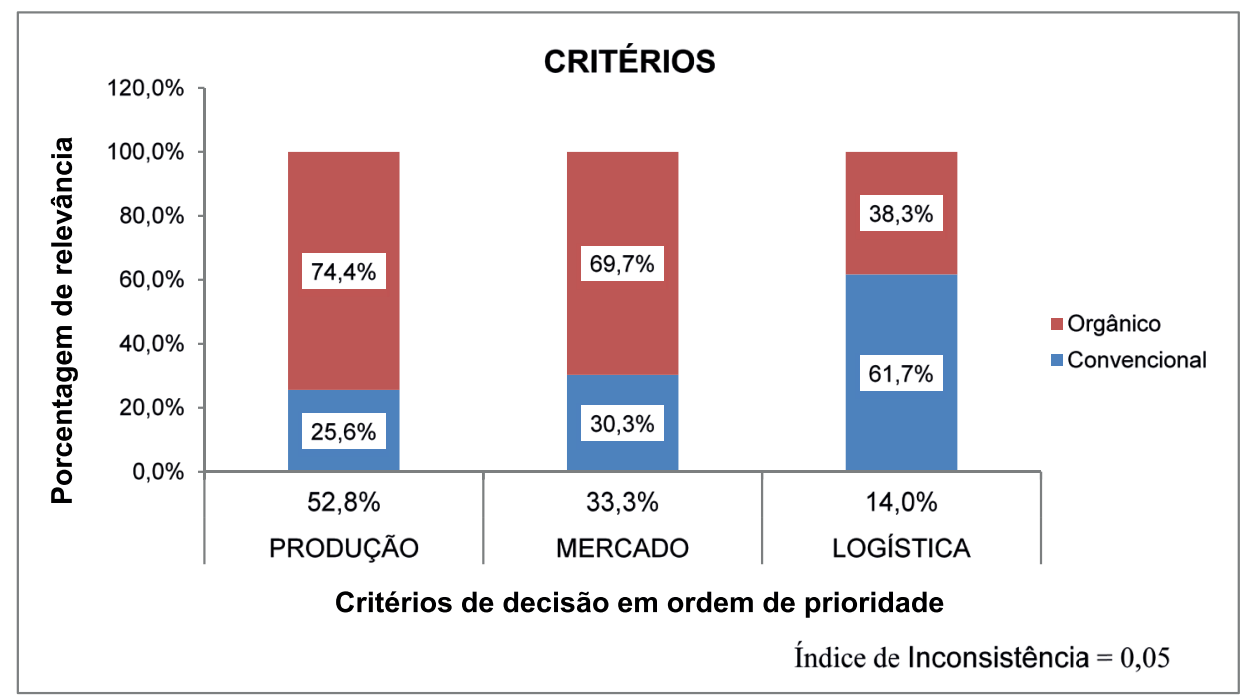

Figura 5. Priorização dos métodos de produção para os critérios propostos.

Nota-se que, dos critérios estabelecidos na estrutura AHP, os produtores priorizam a produção (52,8\%), o mercado (33,3\%), e em seguida a logística (14\%). Os pesos atribuídos resultaram o índice de inconsistência igual a 0,05 , o que demonstra um processo de tomada de decisão consistente.

No critério "produção", os produtores consideram o método orgânico mais vantajoso $(74,4 \%)$ e adaptável à realidade da agricultura familiar. Este resultado é reflexo do objetivo dos pequenos produtores e as suas percepções de sustentabilidade. Segundo Moretti (2014), eles visam ao atendimento do mercado local, a venda direta ao consumidor, e a produção realizada com insumos produzidos na própria propriedade.

Padua (2014) também expõe alguns fatores que motivam os agricultores a optarem pela produção orgânica, como: preocupações concernentes à questão ambiental e sustentabilidade, promoção da segurança alimentar, e interesse no mer- 
cado desses produtos.

Em relação ao critério "mercado", o resultado do modelo decisório também favorece o método orgânico de produção (69,7\%). Acredita-se que o aumento da demanda por produtos saudáveis e ambientalmente corretos seja a justificativa para este resultado. Estudos de Padua (2014) corroboram o resultado, apontando a alta demanda e a possibilidade de melhoria de renda, como os principais elementos motivadores para a escolha do método.

O único critério que prioriza a metodologia convencional foi "logística". Este resultado é justificado com base na análise dos seus subcritérios "armazenamento" e "pontos de distribuição", anteriormente discutidos. Ou seja, não foi atribuída importância ao método orgânico por não os aplicarem à sua realidade.

Diante da análise hierárquica dos critérios e subcritérios estabelecidos para tomar a decisão do método de produção mais adequado aos pequenos produtores, obteve-se o resultado apresentado na Figura 6, elaborado pelo autor, que determina o método de produção orgânico a melhor escolha para a agricultura familiar. O resultado é consistente, considerando o índice de inconsistência geral de 0,06.

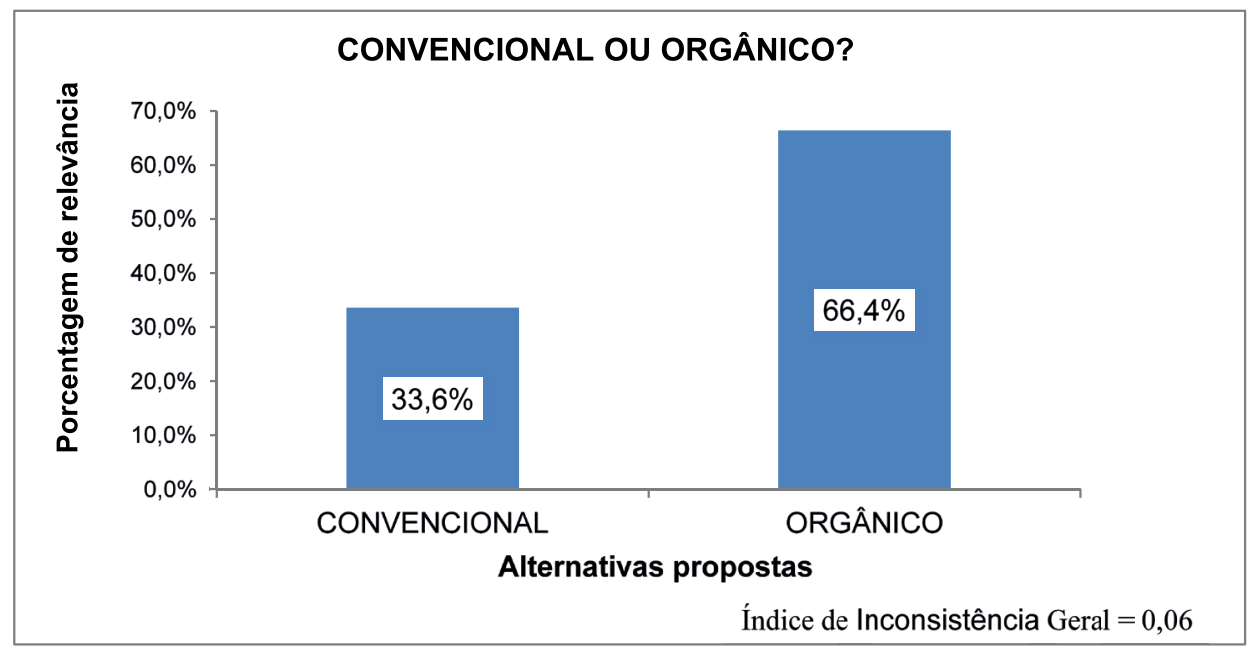

Figura 6. Resultado do método de produção mais adequado aos pequenos produtores. 


\section{CONSIDERAÇÕES FINAIS}

A agricultura familiar ganha reconhecimento não apenas no âmbito econômico e social, mas também na questão ambiental. Novos métodos de produção alternativa têm impactado diretamente a atividade agrícola familiar, e são alvos de estudos e pesquisas em busca da sustentabilidade e de melhores produtos, como é o caso da produção orgânica.

Dos critérios analisados na estrutura proposta, o critério "produção" foi o que teve maior influência no processo decisório. Seus subcritérios (custo, qualidade e assistência técnica) foram priorizados a favor da metodologia orgânica, indicando o método orgânico como o de menor custo de produção e o que proporciona melhor qualidade de produtos.

Sobre o critério "mercado", a metodologia de produção orgânica também foi priorizada com destaque para os subcritérios "preço" e "comportamento do consumidor". A venda direta do produtor ao consumidor elimina atravessadores e pode oferecer valores até mais baixos do que em supermercados da região. Além disso, o aumento da demanda por produtos orgânicos é uma realidade já percebida pelos produtores, indicando o crescimento do mercado de alimentos com maior valor nutritivo e a busca por hábitos de vida mais saudáveis.

De acordo com os resultados apresentados, respondendo à questão da pesquisa, o processo decisório indicou o método orgânico de produção como o mais adequado aos pequenos produtores da agricultura familiar. Pode-se dizer que o resultado é consistente, pois o índice de inconsistência geral do modelo foi 0,06 .

Em relação ao estudo de caso, as perspectivas revelam-se promissoras, com a disponibilização de novos pontos no Hospital Universitário e na feira livre "Parque Alvorada", na cidade de Dourados (MS). Além disso, o processo de certificação dos produtos da comunidade está em andamento junto à APOMS.

Para trabalhos futuros, sugere-se um estudo do comportamento dos consumidores de produtos orgânicos para identificar a situação e percepções do mercado, o que possibilita a elaboração e direcionamento de estratégias para o segmento. Outro ponto a ser explorado é referente ao processo de certificação desses produtos, geralmente muito rígida e custosa aos produtores familiares.

Por fim, considerando as diversas dificuldades da atividade, ressalta-se a ne- 
cessidade de integração de esforços, tantos dos produtores, quanto das instituições e entidades de assistência técnica, com o propósito de desenvolver a agricultura familiar orgânica. $\mathrm{O}$ incentivo e acompanhamento dos pequenos agricultores orgânicos tem papel fundamental nesse processo.

\section{REFERÊNCIAS}

ANDRADE, L.; BERTOLDI, M. Atitudes e motivações em relação ao consumo de alimentos orgânicos em Belo Horizonte-MG. Food Technology, IV, 31-40. 2012.

AZEVEDO, E. Alimentos orgânicos: ampliando os conceitos de saúde humana, ambiental e social. Unisul, 2006.

BUAINAIN, A. M.; ALVES, E.; SILVEIRA, J. M.; NAVARRO, Z. O mundo rural no Brasil do século XXI: a formação de um novo padrão agrário e agrícola. Brasília: Embrapa, 2014.

CAPORAL, F. R.; COSTABEBER, J. A. Agroecologia e sustentabilidade. Base conceptual para uma nova Extensão Rural. In: World Congress of Rural Sociology. 2001. p. 114-123.

FAO - Organização das Nações Unidas para Alimentação e a Agricultura. Ano internacional da agricultura familiar 2014. Disponível em: < http://www.fao.org/ family-farming-2014/pt/> . Acesso em: 24 ago. 2014.

FAO - Organização das Nações Unidas para Alimentação e a Agricultura. O estado da segurança alimentar e nutricional no Brasil - SOFI: um retrato multidimensional. Relatório 2014. Brasília, 2014a.

FCP - Fundação Cultural Palmares. Comunidades quilombolas. Disponível em: <http://www.palmares.gov.br/?page_id=88\#> . Acesso em: 24 ago. 2014.

GIL, A. C. Métodos e técnicas de pesquisa social. São Paulo: Atlas, 2010.

GRANEMANN, S. R.; GARTNER, I. R. Seleção de financiamento para aquisição de aeronaves: uma aplicação do método de análise hierárquica (AHP). Transportes, v. 6, n. 1, 2010. 
IBGE - Instituto Brasileiro de Geografia e Estatística. Censo agropecuário 2006: Brasil, grandes regiões e unidades da Federação. Rio de Janeiro: MPOG, 2009.

IBGE - Instituto Brasileiro de Geografia e Estatística. Mato Grosso do Sul. Disponível em: < http://www.ibge.gov.br/estadosat/perfil.php?sigla=ms > . Acesso em: 04 ago. 2015.

INCRA - Instituto Nacional de Colonização e Reforma Agrária. A agricultura familiar encerra 2013 com recordes e define novas metas no ano internacional do setor. Disponível em: <http://www.incra.gov.br/agricultura-familiar-encerra-2013-com-recordes-e-define-novas-metas-no-ano-internacional-do-setor $>$. Acesso em: 24 ago. 2014.

ISHIZAKA, A.; LABIB, A. Review of the main developments in the analytic hierarchy process. Expert systems with applications, v. 38, n. 11, p. 14336-14345, 2011.

ISHIZAKA, A.; LABIB, A. Quilombolas. Disponível em: < http://www.incra.gov.br/ estrutura-fundiaria/quilombolas $>$. Acesso em: 24 ago. 2014.

JESUS, P.; TIRIBA, L. Cooperação. In: CATTANI, A. D.; LAVILLE, J.; GAIGER, L. I.; HESPANHA, P. (Org.). Dicionário Internacional da Outra Economia. Coimbra: Almedina, 2009. v. 1, (Centro de Estudos Sociais da Universidade de Coimbra), p. 80-85.

MAPA - Ministério da Agricultura, Pecuária e Abastecimento - Brasil. Número de produtores orgânicos cresce $\mathbf{5 1 , 7 \%}$ em um ano. Disponível em: $<$ http://www. agricultura.gov.br/comunicacao/noticias/2015/03/numero-de-produtores-organicos-cresce-51porcento-em-um-ano > . Acesso em: 26 set. 2015.

MDA - Ministério do Desenvolvimento Agrário - Brasil. Plano safra da agricultura familiar 2012/2013. Disponível em: < http://portal.mda.gov.br/planosafra/arquivos/view/Cartilha_Plano_Safra.pdf $>$. Acesso em: 17 jun. 2015.

MORETTI, S. A. L. Território da produção orgânica no mundo da mercadoria. Dourados: Ed. da UFGD, 2014.

OSÓRIO, F. H. Agricultura familiar e desenvolvimento rural. Seminário: agricultura familiar em Portugal. Campo Pequeno, 31 de maio de 2014.

PADUA, J. B. Produção e comercialização de produtos orgânicos pela agricultura familiar em Mato Grosso do Sul. Dissertação (Mestrado em Agronegócios) 
- Universidade Federal da Grande Dourados, Dourados, 2014.

SAATY, T. L. Decision making with the analytic hierarchy process. International Journal of Services Sciences, v. 1, n. 1, p. 83-98, 2008.

SAATY, T. L. How to make a decision: the analytic hierarchy process. European Journal of Operational Research, Pittsburgh, v. 48, n. 1, p. 9-26, 1990.

SAATY, T. L. Método de análise hierárquica. [S.1.: S.n.], 1991.

SAATY, T. L. The analytic hierarchy process: what is and how it is used. Mathematical and Computer Modelling, Pittsburgh, v. 9, n. 3, p. 161-176, 1987.

SAATY, T. L. The analytic hierarchy process: planning, priority setting, resources allocation. New York: MacGraw, 1980.

SAHOTA, A. The Global Market for Organic Food \& Drink. The world of organic agriculture. Statistics and emerging trends 2015. FiBL-IFOAM Report/H. Willer, J. Lernoud. Frick and Bonn, 2015.

THESEK, C. N. L. Cultura da Cooperação: uma abordagem psicossocial em uma cooperativa de trabalho. Revista Gestão e Tecnologia, v. 6, n. 1, 2006.

UFGD - Universidade Federal da Grande Dourados. Orgânicos produzidos em projeto de extensão agora são vendidos também na Unidade 1. Disponível em: $<$ http://www.ufgd.edu.br/noticias/organicos-produzidos-em-projeto-de-extensao-agora-sao-vendidos-tambem-na-unidade-1-1>. Acesso em: 25 ago. 2014.

WILLER, H.; LERNOUD, J. The world of organic agriculture: statistics and emerging trends 2015. FiBL-IFOAM Report/H. Willer, J. Lernoud. Frick and Bonn, 2015.

Recebido em: 07/01/2016 Aceito em: 05/11/2017 